\title{
Distribution and niche of Macrolepiota excoriata in Asia
}

\author{
Vyacheslav Vlasenko ${ }^{1 *}$, Dejidmaa Turmunkh ${ }^{2}$ \\ ${ }^{1}$ Central Siberian Botanical Garden SB RAS, 630090 Novosibirsk, Russia \\ ${ }^{2}$ Plant Protection Research Institute of Mongolia, 17024 Ulaanbaatar, Mongolia
}

\begin{abstract}
We defined the regularities in spatial distribution of Macrolepiota excoriata based on the occurrence data, as well as bioclimatic characteristics in order to control species status in the natural environment. Points of presence occurring in the steppe of Central Altai Mountains have the most optimal conditions for M. excoriata in Asia.
\end{abstract}

\section{Introduction}

The Macrolepiota genus contains approximately 45 species. Macrolepiota excoriata is a fungus from the Agaricaceae family, growing on soil (Fig 1).

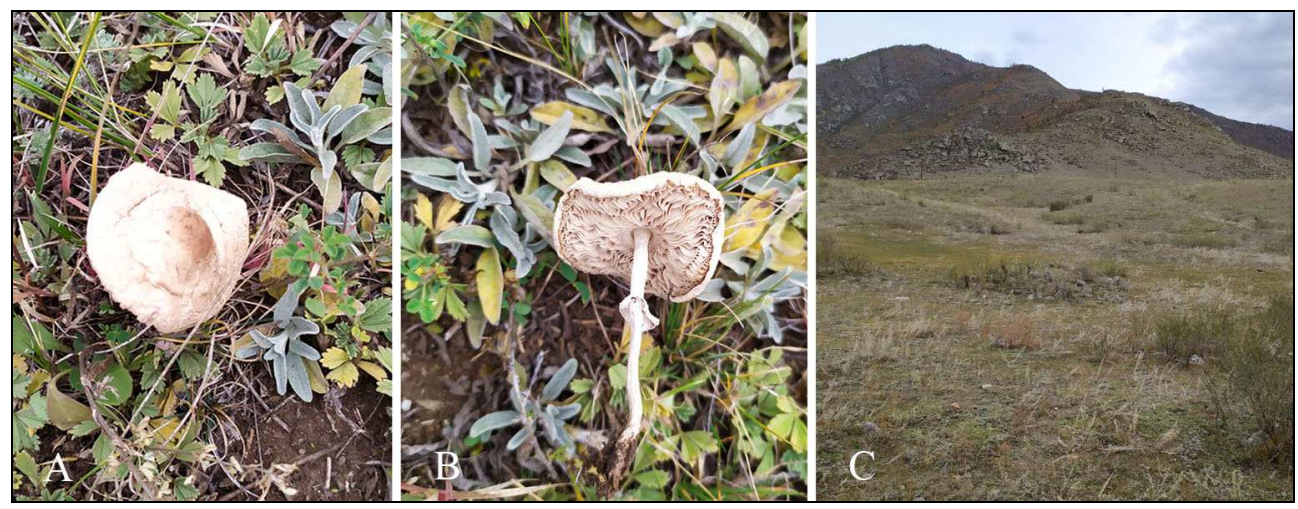

Fig. 1. A, B - Fruiting bodies of M. excoriata. C - Mountain steppe, is a typical habitat of species in Mountains of Central Altai.

Macrolepiota excoriata is widespread in Europe, occasionally observed in Asia; the species was also recorded in North America and Australia (Fig 2).

\footnotetext{
*Corresponding author: vlasenkomyces@ mail.ru
} 


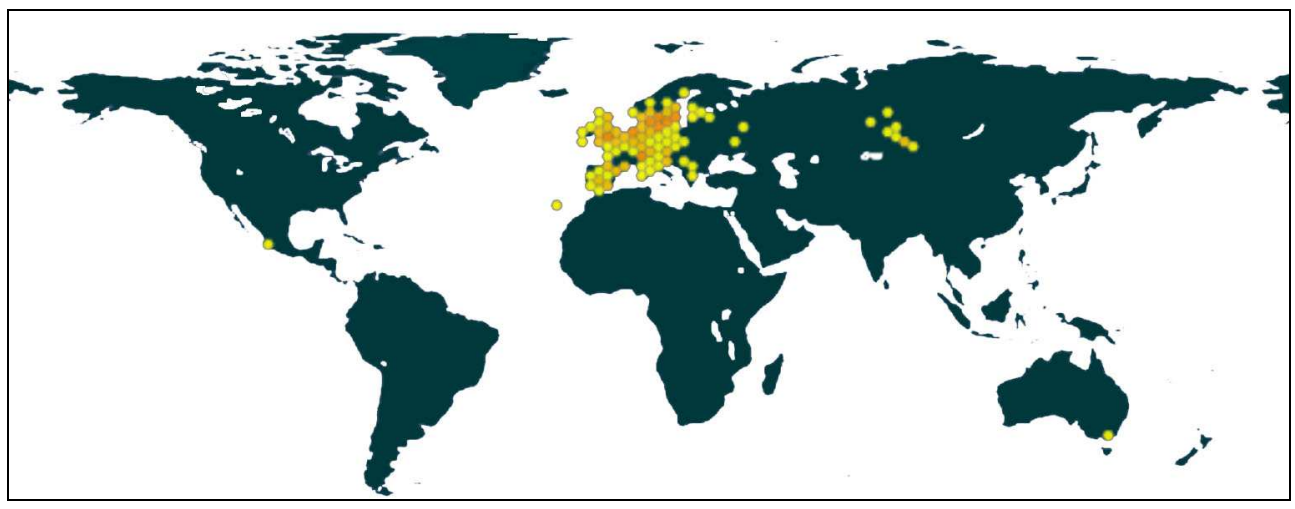

Fig. 2. Map of worldwide distribution of M. excoriata according to GBIF data [1].

Typical habitats of this species in Asia - steppes and grassland (according to our observations).

The study of $M$. excoriata is of fundamental importance for understanding the patterns of distribution and ecology of species associated with the steppe biome. Such species can become endangered due to anthropogenic impact on their habitats. But if a species is ecologically plastic, then its niche can expand due to global climate change, which can lead to the colonization of habitats with similar environmental parameters.

Thus, the species of arid habitats can become model objects in ecological studies on the adaptation of spore microorganisms to the modification of environmental conditions during the transformation of their habitats, as well as a result of climate change, including those accompanied by desertification processes.

Macrolepiota excoriata in Russia, was recorded in the Moscow Region, Tomsk Region, Novosibirsk Region, Altai Territory, and the Republic of Altai. Georeferencing data for most records are absent. Also, the records are based on observations, which does not exclude the incorrect identification of the species.

We present three new localities of $M$. excoriata for Central Altai. Our record of $M$. excoriata in the Republic of Tuva is the first in this region and in Inner Asia.

\section{Materials and methods}

\section{Field studies}

We obtained data on the distribution of the studied fungal species based on the fruiting bodies collected by us during 2019-2020 in expeditions. We carried out our fieldwork in the south of Western Siberia in Republic of Altai (in 2019, 2020) and in Republic of Tuva (in 2020). Voucher specimens of the studied species are stored in the MG Popov Herbarium (NSK), Novosibirsk, Russia.

\section{Morphological examination}

We performed the initial morphological examination of $M$. excoriata fruiting bodies using Carl Zeiss Axioskop-40 light microscope.

Biodiversity data overview and Study area

We obtained the six locations for species from the Global Biodiversity Information Facility (GBIF). We used only records supported by geographic coordinates. In total, we included 10 locations of M. excoriata in Asia, including our four locations (all points do not do not fall into one raster cell). Distribution of M. excoriata in Asia and locations used in the niche modeling analysis shows in Fig 3.

SDM algorithms, predictor type, software and data used 
We used the computer program DIVA-GIS [2] for mapping and geographic data analysis (https://www.diva-gis.org/). We downloaded data on the relief and the heights of the studied locations, as well as global data on current climat ( 1950-2000) from https://www.diva-gis.org/Data and https://www.diva-gis.org/climate, source Worldclim, version 1.3. All the 19 environmental layers of Bioclim, BIO1-BIO19 [3] constructed using the DIVA-GIS with 2.5-minute resolution (30 arc seconds square) encompassed most of the Asia.

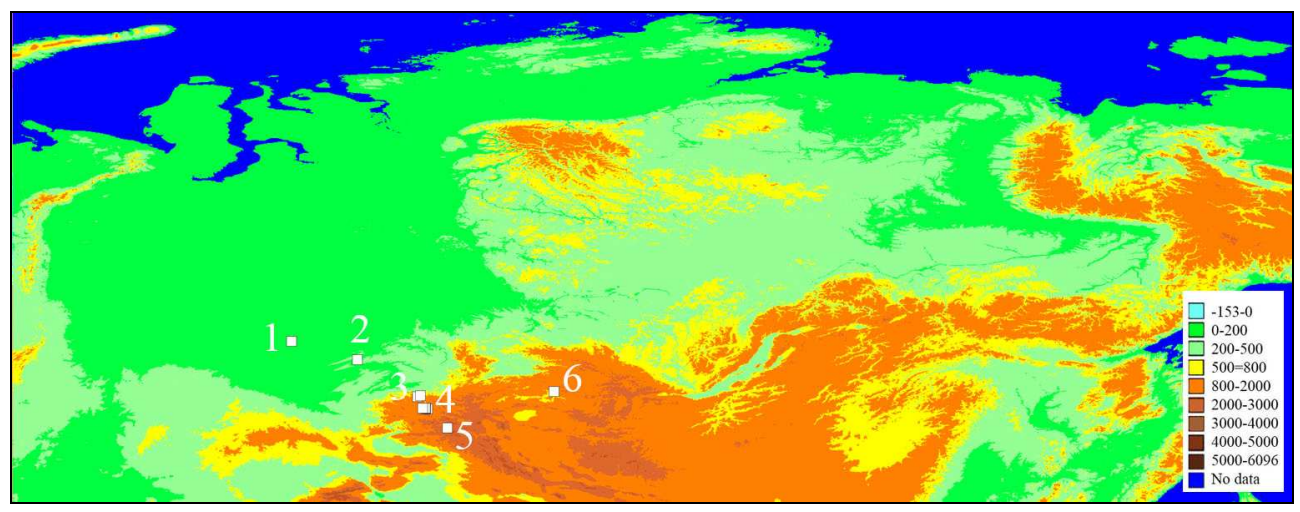

Fig. 3. Locations of M. excoriata in Asia. Forest-steppe zone of Western Siberia in the Novosibirsk Region - Loc. $1\left(55.3516^{\circ} \mathrm{N}, 76.9256^{\circ} \mathrm{E}, 102 \mathrm{~m}\right), 2\left(54.0941^{\circ} \mathrm{N}, 81.4588^{\circ} \mathrm{E}, 114 \mathrm{~m}\right)$. Republic of Altay: Locs. 3 - Northern Altai $\left(51.5703^{\circ} \mathrm{N}, 85.5558^{\circ} \mathrm{E}, 497 \mathrm{~m} ; 51.6395^{\circ} \mathrm{N}, 85.7642^{\circ} \mathrm{E}, 383 \mathrm{~m}\right)$; Locs. 4 - Central Altai $\left(50.7261^{\circ} \mathrm{N}, 86.2468^{\circ} \mathrm{E}, 779 \mathrm{~m} ; 50.7639^{\circ} \mathrm{N}, 86.1076^{\circ} \mathrm{E}, 850 \mathrm{~m} ; 50.7790^{\circ} \mathrm{N}\right.$, $\left.86.0810^{\circ} \mathrm{E}, 869 \mathrm{~m} ; 50.7903^{\circ} \mathrm{N}, 85.9048^{\circ} \mathrm{E}, 952 \mathrm{~m}\right)$; Loc. 5 - Southeastern Altai $\left(49.4285^{\circ} \mathrm{N}\right.$, $\left.87.5945^{\circ} \mathrm{E}, 2087 \mathrm{~m}\right)$. Republic of Tuva: Loc. 6 - Sayans Mts $\left(51.9167^{\circ} \mathrm{N}, 94.9037^{\circ} \mathrm{E}, 986 \mathrm{~m}\right)$. The colors corresponds to the height above sea level (decoding in the legend).

We constructed the climatic profile of $M$. excoriata in Asia using the BIOCLIM method. This method developed by H. Nix [4] constructs histograms of bioclimatic variables that reflect species climate profile. The DIVA-GIS software implements the BIOCLIM method.

\section{Results and Discussion}

The climatic niche of a species bases on the identification of the climatic characteristics of the locations where the studied species appeared [5].

We generated the frequency histograms based on bioclimatic variables BIO1 (Annual Mean Temperature) and BIO12 (Annual Precipitation) (Fig 4). The histograms show the distribution of $M$. excoriata along the customized ranges for selected climatic variables.

We carried out the modeling of a two-dimensional niche for M. excoriata based on bioclimatic variables BIO1 (Annual Mean Temperature) and BIO12 (Annual Precipitation) (Fig 5).

We adjusted the width of the niche by changing the percentile values. We changed the boundaries of the two-dimensional niche by changing the percentile to the limit when the points went outside the range values for 19 bioclimatic variables (in the model, the points of presence changed color to red). In this way we changed the limits of the two-dimensional niche within $0.000-0.001-0.112-0.223(100 \%-70 \%-50 \%-40 \%$ observations presented in a niche). 

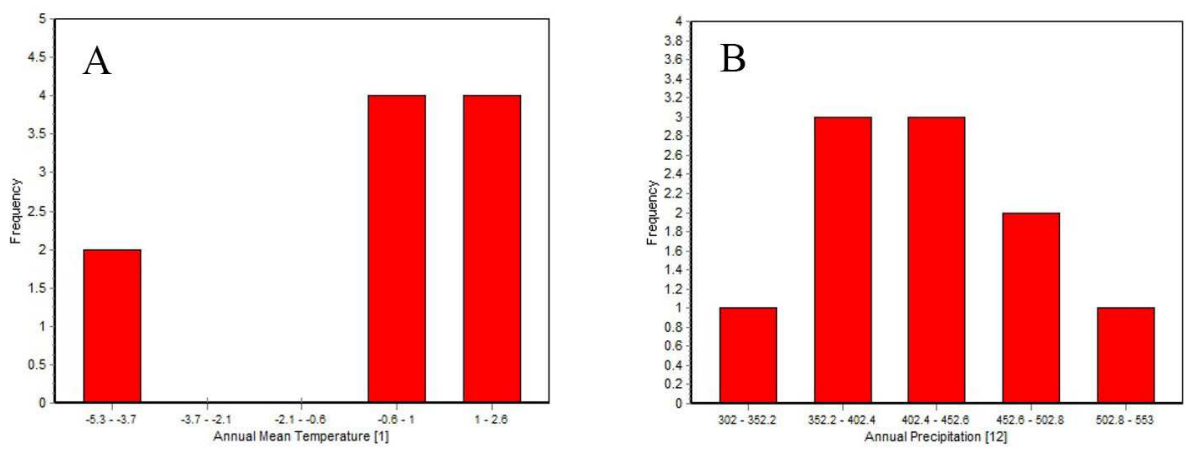

Fig. 4. Frequency histograms, which show the distribution of M. excoriata along customized ranges. A - Annual Mean Temperature (BIO1), B - Annual Precipitation (BIO12). Axis of abscissa - the factor strength. Ordinate axis - the frequencies.

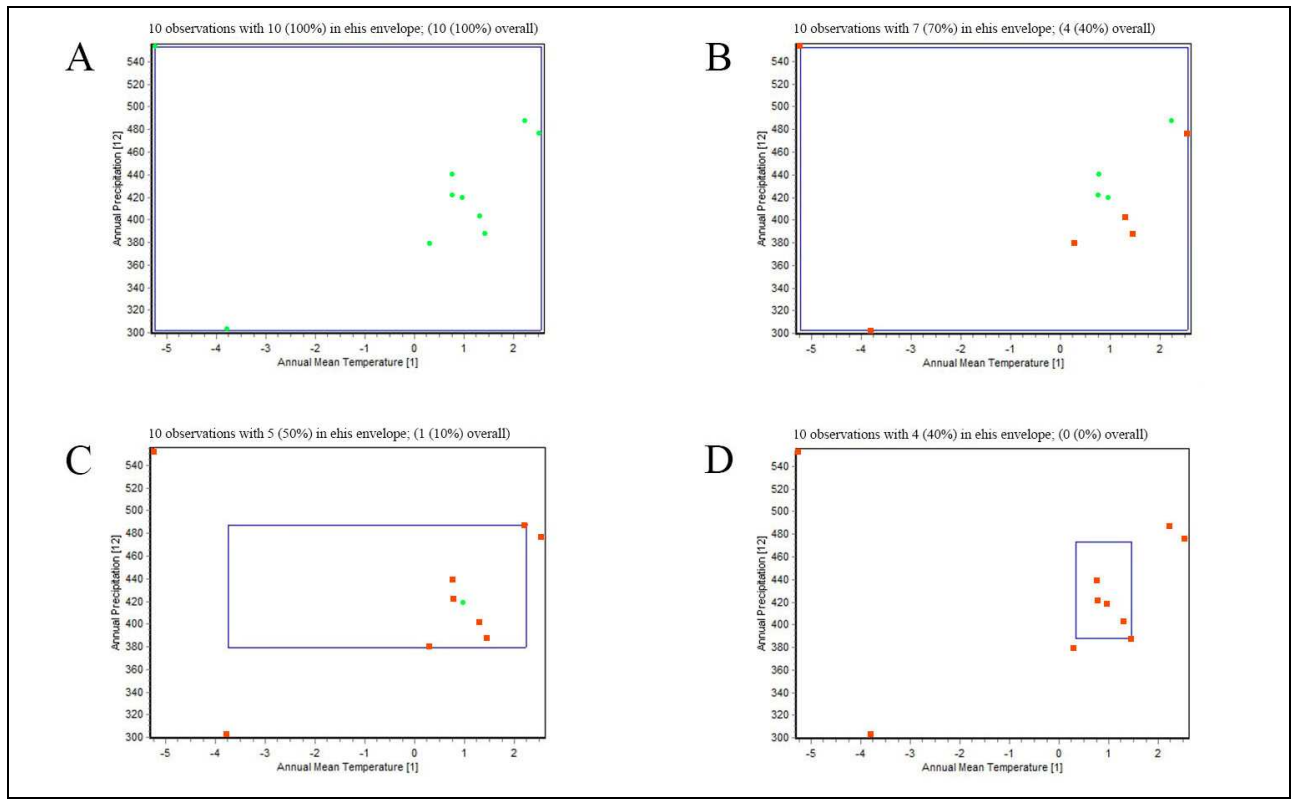

Fig. 5. Visualization of a two-dimensional niche for $M$. excoriata based on two climatic variables using the Envelope method. Limits of the two-dimensional niche: A 0.000, B 0.001, C 0.112, D 0.223 . Blue rectangle is the climatic niche. The green points represent the presence points with a climate profile within the range limits of all the 19 Bioclim climatic variables. Red square within the blue rectangle represent presence points with a climate profile within the values of the range limits for the selected variables (Annual Mean Temperature and Annual Precipitation), but with one or more values laying outside the range limits of the other 17 Bioclim variables. Red square outside the blue rectangles represent presence points with a climate profile with one or more values laying outside the range limits of the 19 Bioclim climatic variables.

We narrowed the climatic niche in order to determine the core of the climatic niche with the most favorable habitat parameters for the species, based on the selected bioclimatic variables (Fig 6). 


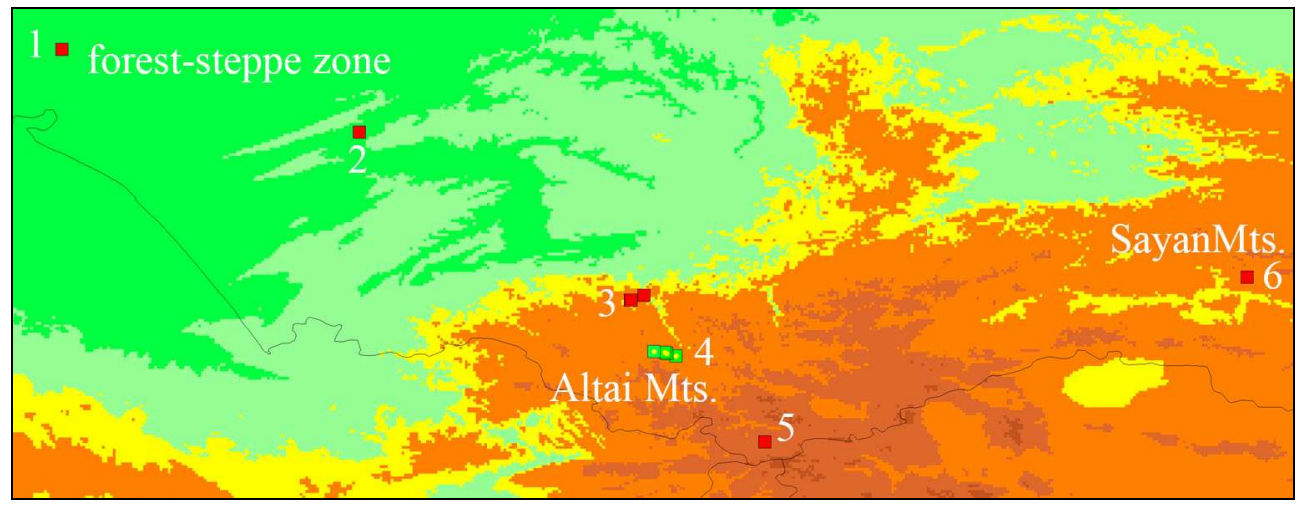

Fig. 6. The environment core of the species range (green points) of M. excoriata in Asia with the twodimensional niche limits $=0.223$.

\section{Conclusions}

The constructed model of the species climatic niche allow us to conclude that the geographical distribution of $M$. excoriata, in addition to the presence of a suitable habitat type (steppe or steppe subject to grazing), related with environmental factors that are optimal for existence of this species.

The constructed model showed that the points of presence occurring in the steppe in intermontane depressions and lowlands between mountain ranges in Central Altai represent the core of the M. excoriata climatic niche in Asia based on the selected bioclimatic variables. Other areas of Asia in the forest-steppe zone of Western Siberia in the Novosibirsk Region, as well as mountainous regions, including Sayans in the Republic of Tuva and Northern Altai and Southeastern Altai (Ukok Plateau) in the Republic of Altai have less favorable environmental conditions for M. excoriata.

Acknowledgements. The work was funded by RFBR and MCESSM according to the research project 19-54-44002 Mong_T.

\section{References}

1. Macrolepiota excoriata (Schaeff.) Wasser in GBIF Secretariat. GBIF Backbone Taxonomy. Checklist dataset. https://www.gbif.org/species/2536733 (2021)

2. R. J. Hijmans, L. Guarino, P. Mathur. DIVA-GIS Version 7.5 Manual. Available from http://diva-gis.org/docs/DIVA-GIS_manual_7.pdf (2012)

3. R. J. Hijmans, S. E. Cameron, J. L. Parra, P. G. Jones, A. Jarvis, Int. J. Climatol., 25 (2005)

4. H. A. Nix, Australian flora and fauna, Series 7, Atlas of elapid snakes of Australia (Australian Government Publishing Service, Canberra, 1986)

5. X. Scheldeman, M. Van Zonneveld, Training manual on spatial analysis of plant diversity and distribution (Biodiversity International, Rome, 2010) 